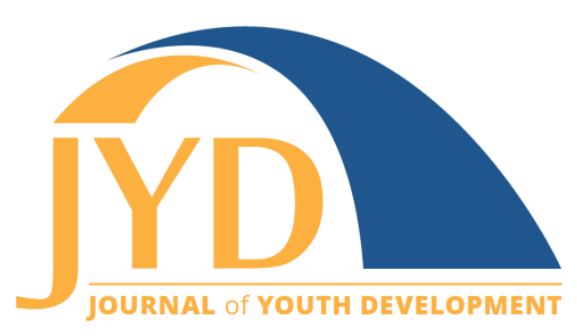

http://jyd.pitt.edu/ | Vol. 15 Issue 4 DOI 10.5195/jyd.2020.877 | ISSN 2325-4017 (online)

\title{
All Hands on Deck: Building a Sustainable Volunteer Program
}

\author{
Susan Restler \\ ALLINBKLYN \\ susan.restler@gmail.com \\ Lauren Glant \\ ALLINBKLYN \\ lauren.glant@gmail.com
}

\begin{abstract}
Youth-serving organizations that engage volunteers offer them varied roles. In volunteer-dependent organizations, volunteers are the vital backbone of service delivery, without whom the organization would be hard-pressed to exist. At the other end of the spectrum are organizations whose paid staff provide all services and whose volunteers play episodic, narrowcast roles. Sitting in between are those organizations where volunteers provide added value to the work of paid staff, expanding services to youth that the organization may not otherwise afford. The volunteer value-add model is as challenging as it is appealing. It often frustrates and disappoints both the organization and the volunteers, not surprisingly because it requires time and attention to design and support well. In this article we examine why value-add programs so often fail and look at the critical elements of the volunteer value-add model. We describe one program, READ718, whose design exemplifies the key dimensions that value-add organizations need to consider and adapt if their programs are to meet the needs of staff, volunteers and especially youth. Because there is some risk to youth in poorly designed and inadequately supported volunteer programs, as well as ramifications for organizational reputation, we feel that greater clarity about what it takes to mount a robust initiative is vital and worthwhile, even if the result is that some organizations reflect and elect to abandon this path.
\end{abstract}

Key words: sustainable volunteer program design, READ718, ALLINBKLYN, volunteer program model

(c) $\mathrm{EY}$ New articles in this journal are licensed under a Creative Commons Attribution 4.0 License. This journal is published by the University Library System, University of Pittsburgh and is cosponsored by the University of Pittsburgh Press. The Journal of Youth Development is the official peer-reviewed publication of the National Association of Extension 4-H Youth Development Professionals and the National AfterSchool Association. 


\section{All Hands on Deck}

\section{Introduction}

\section{Comparative Context}

Our work affirms and advances several models of effective volunteer program design and administration. The ISOTURE model, first posited in 1971 (Boyce, 1971); the Volunteer Management Cycle (Lawson and Lawson, 1987); and the GEMS Model of volunteer administration (Culp et al., 1998), among others, address, as we do, program design, volunteer recruitment and training, and volunteer recognition and evaluation. In this article we offer several recommendations to better assure that a volunteer initiative will be sustainable and a net advantage to an organization. At the outset, we recommend that the volunteer program be integral to the mission of the organization and endorsed by everyone from the board to employees, even those not directly impacted by the program. This assures the program is fully supported within the organization. We further suggest that volunteers be viewed as partners in the provision of service to youth, and that we move beyond recognition and evaluation to integrate volunteers actively in program improvement. Volunteers who influence the shape of a program through their own feedback and who feel that they are growing personally, notably in cultural competence, are the foundation of a sustainable program.

\section{Origin of the Work}

The work described here originated in a research project we undertook as members of the ALLINBKLYN women's giving circle. Circle members pool funds annually to support a group of non-profit organizations that are based in Brooklyn, New York, and predominantly serve youth and young adults. In 2018, in an effort to deepen and potentially expand the impact of ALLINBKLYN, a small group of members examined the question of what it takes to design a volunteer program that works; that is, a program that meets the needs of both the organization and the volunteers. The ideas presented here emerged from a yearlong collaboration among four giving circle members and four leaders at Brooklyn nonprofits that all work with youth and young adults. One of the leaders is an executive director and three are directors of advancement. All the organizations are small: a high school for girls from marginalized communities, a community-based nonprofit serving a public housing community, an environmental workforce development program, and a provider of essential goods to new parents. ALLINBKLYN members collectively brought extensive experience as program volunteers, including as board members and chairs, as well as their own work experience in law and finance. 


\section{All Hands on Deck}

We met as a full group to frame the issues around successful volunteer engagement and then worked in teams to research these, using both a literature review and interview process. We brought our findings together to draw the conclusions and recommendations offered here.

Because successful volunteer-dependent organizations employ a set of best practices in sustainable program design, we suggest that value-add programs begin with this framework in mind and adapt its elements to their context. In this article we mobilize one aspect of our research-a case study of READ718, a volunteer-dependent organization-as a way to describe both the key elements of a sustainable volunteer program and how to adapt them to a valueadd context.

\section{Why Volunteer Programs Fail}

Volunteer programs fail in nonprofit organizations whose foci range from the environment to the arts, from serving the elderly to serving youth. A common thread among these faulty volunteer initiatives is that the programs have not been woven into the strategic fabric of the organization in a way that supports its mission. Instead, volunteers may be perceived as a gateway to additional donors or potential funding. Thus, when an important or potentially important volunteer comes forward to propose a role that is off-mission or a low priority, the answer is "yes," when it could be "yes, but because of our strategic priorities how about . . . ?" (Smith, 2013). The diversion of resources to attend to a low priority request can be costly to the mission and discouraging for staff.

Friction or conflict between staff and volunteers can also develop when there is a lack of strategic vision regarding the use of volunteers. This arises when staff members have not been involved in developing the volunteer program, or because roles have not been sufficiently defined to avoid conflict (Netting et al., 2004). The toll this takes on staff morale can be significant, which in turn can impact the provision of service (Eisner et al., 2009).

Another understandable but problematic choice is to assign management of a volunteer program to a staff member who is already fully occupied. Eisner et al. (2009) describe a youthservice organization in Florida that gave volunteer management responsibility to a "busy receptionist." In instances like this, volunteers rarely receive the attention they require to be effective, and staff can feel both burdened by the additional and unexpected responsibilities and frustrated by a lack of clarity regarding the role of the volunteers they are overseeing. 


\section{All Hands on Deck}

These various conditions obviously lead to less-than-optimal experiences for volunteers. Galindo-Kuhn and Guzley (2002) identify four dimensions of volunteer satisfaction: organizational support, participation efficacy, empowerment, and group integration. They found that participation efficacy and group integration were most significantly correlated with volunteer satisfaction and commitment to remain. Nelson et al. (2007) found that other than changed personal circumstances, discontent with supervision was the deciding factor for volunteers who chose not to return. Volunteers can be frustrated if the work they are asked to do does not capitalize on their skills or, on the other hand, if it requires training that they lack (Eisner et al. 2009). Rogelberg et al. (2010) suggest that volunteer satisfaction and staff satisfaction are inextricably intertwined. All of these potential "potholes" serve to highlight the advantage of designing and maintaining a thoughtfully crafted and integrated volunteer program and alert us to the risks of failing to do so, particularly the potential impact on youth of engaging with adults who are underprepared and under-supported.

What follows is a description of the volunteer-dependent, youth-serving organization: READ718. We describe six elements of its program that our investigation independently identified as elements that must figure in some way in order for a volunteer value-add program to function well. These elements address both organizational and volunteer commitment and include mission advancement, staff engagement, volunteer recruitment and preparation, volunteer support, and collaborative program impact assessment and design adaptation.

A volunteer-dependent organization explicitly synchronizes its mission and staff commitment with its volunteer program. For an organization whose work with youth is primarily carried out by paid staff, the addition of a volunteer value-add program must be determined to be missioncritical. Without this determination by leadership, board, and staff, the organization risks underinvesting in what we believe are the vital elements of excellent program design.

\section{READ718: A Youth Literacy Tutoring Program}

\section{Program Origins}

READ718 was founded in 2015 by Emily Kirven. The inspiration for the program came when Emily taught English in a school located in an economically poor Brooklyn neighborhood. Whereas she wanted to teach poetry and fiction and discuss themes and writing style, she found many of her students struggled to read at grade level. Realizing that the families of her 
students often lacked the means to secure a tutor, she decided to establish a nonprofit literacy coaching service.

READ718 is open to any student with financial need who is reading below grade level. Emily and her small paid staff are literacy specialists, qualified to assess youth and design curricula that address individual needs. The one-on-one work with youth is conducted exclusively by volunteer tutors.

\section{Organizational Commitment}

Volunteer-dependent organizations, while excellent exemplars of volunteer program design, by definition do not have to work to reconcile the volunteer role with organizational mission because their very survival depends on building a robust and sustainable experience for youth and volunteers alike. In the case of READ718, the executive director and staff are devoted to supporting the effectiveness of the volunteer tutors. An organization considering initiating or evaluating a value-add program can take a cue from the volunteer-dependent organization by formally determining that an investment in a youth-serving volunteer program will materially advance the mission. A strategic planning process provides a useful locus for considering a commitment to a value-add program. The endorsement of and engagement with a volunteer program by both organizational leadership and staff is a sine qua non of a successful program design. It should assure that necessary resources are devoted to the effort and that staff will embrace rather than undermine the volunteers' work. If, based on the overall mission and prevailing strategic priorities of the organization, leadership does not feel that integrating volunteers will add significant value to the youth its program serves and does not take the time to build support among staff for the volunteer role, then a program is likely doomed.

\section{Volunteer Commitment}

\section{Recruitment}

Referrals from enthusiastic volunteers are a desirable way to build the ranks; however, recruitment generally is required to launch a program and, indeed, outreach may be a permanent part of a sustained volunteer program. Here an organization walks a fine line between overselling an opportunity and discouraging applicants. Advertising the importance of the program and its impact on youth as well as the key features of the role-the nature of the work, necessary qualifications, and time commitment-makes sense at this early juncture. 


\section{All Hands on Deck}

Over its four-year existence READ718 has recruited tutors successfully using several online sites including Volunteer Match, Idealist, and NYC Service, as well as word-of-mouth. They have also distributed flyers at colleges and in the community, although this has done more to raise awareness than yield potential tutors. The disappointment with these recruitment tactics, the implications of which we will discuss in more detail, is that the vast majority of volunteers are White, while the youth served by READ718 are predominantly Black and Brown. Consequently, in response to research demonstrating the benefit to youth of working with adults that reflect their racial and ethnic make-up (Lindwall, 2002), READ718 has initiated additions to its outreach, approaching churches and local chapters of historically Black fraternities and sororities to recruit more tutors of color to the program.

\section{Application and Selection}

It is awkward, challenging, and perhaps even somewhat risky in terms of financial support, to turn down an interested volunteer. Ideally the organization conveys its needs and expectations in a clear and compelling way that is focused on the needs of and benefits for youth so that the potential volunteer either opts out, recognizing that the fit is not good, or opts in, with an appreciation for the nature of the commitment.

READ718 asks interested potential tutors to complete an application, which makes clear the qualifying criteria: Applicants must be high school graduates with strong literacy and communication skills and a passion for the work. Two key questions on the application are: "Why do you want to be a READ718 tutor?" and "What qualities do you have that would make you an excellent literacy tutor?" The staff pays close attention to each candidate's responses and uses them to probe candidates at an initial face-to-face meeting. The written answers and further discussion crystalize the nature of the commitment for the applicant. Any staff hesitation concerning a volunteer's motivation, qualification or commitment is noted for further internal discussion if the individual continues through the process.

The point here is not to intimidate potential volunteers with an involved application process. Rather, by posing a small number of pointed questions, READ718's process causes each person to pause and reflect on the seriousness of the commitment they are potentially making.

Those who complete the application are invited to an orientation at the storefront. Here, the staff meet each person, form an impression, and more importantly, establish a connection that might inspire a potential tutor to make the commitment that each tutee needs. At the 


\section{All Hands on Deck}

orientation Emily and the staff describe in detail how the program works, what the volunteers can expect of the tutees and of the READ718 staff, and what will be asked of them.

The backbone of the program is a 10 -week cycle consisting of twice-weekly 80 -minute sessions that take place in the bright storefront that houses the program. Tutors and tutees sign up for one cycle at a time. READ718 hopes, and indeed it has been the case, that students return; however, tutors find that the well-defined and limited time commitment is an attractive feature of the volunteer opportunity. Nonetheless, some people withdraw during orientation, as they recognize that the nature of the work or the time demand is not for them. This is, in fact, a good thing, as the decision not to participate is the applicant's and not the organization's. For those who persist, READ718 secures two references and a background check.

\section{Preparation}

Once an invitation to participate in any program is offered and accepted, the first step is to prepare the volunteer for the role they will play with youth. Where appropriate, there is training in the specific skills that are to be shared with youth, but it is also important to orient volunteers to the organization's culture and structure and to forge an explicit bond with staff in their shared goal of serving youth.

In the case of READ718, new tutors are required to participate in a 31/2-hour training session that takes place on a Saturday at the storefront. Most of that time is devoted to preparing the tutors for the work they will do as literacy coaches. They learn about the types of skills they will work with youth to develop and how to write up notes on youth progress that will enable staff to tailor ongoing sessions.

Because, as noted above, tutor recruitment has yielded a predominantly White tutor pool (85$95 \%$ ), while the youth are predominantly Black and Brown (90\% or more), READ718 addresses diversity, equity and inclusion work in its preparation session. The objective is to assure that the volunteers are invested and effective literacy tutors who interact with youth in appropriate and affirming ways.

In this regard, READ718 aligns with other youth development organizations that are paying increasing attention to the cultural and socioeconomic differences that often exist among staff, volunteers, and youth. Nationally, nonprofit staff and leadership are predominantly White, including, notably, organizations whose mission and programming serve communities of color 


\section{All Hands on Deck}

(Dubose, 2014), and this often extends to volunteers in those organizations. This difference in background, perspective and assumptions can lead not only to misunderstanding and unintended micro-aggressions by well-meaning adults, but also to roadblocks in the overall success and personal growth of minority youth (Lindwall, 2002). Because the risks may be even greater when volunteers engage as part of a value-add program, special care should be taken to ensure that cultural competency training is undertaken when appropriate.

Some organizations may be concerned that adding training in diversity, equity, and inclusion will strain both staff, who already have numerous responsibilities, and volunteers, who may not be comfortable in conversations around issues of race, class and privilege (DiAngelo, 2018). In our experience, however, if well-conceived, this experience is welcomed by staff and volunteers alike.

In the READ718 preparation session, volunteers discuss ways to build cultural competence by examining implicit bias and "norms" that may be norms for only one racial and socio-economic group. Volunteers have expressed appreciation and endorsement for this module, which focuses on an examination of several scenarios that are drawn from actual READ718 tutorial interactions. The prospective tutors reflect on the exchanges and discuss alternate ways in which dialogue might unfold.

\section{Sustaining Engagement}

Even with advance preparation, questions and issues inevitably arise and opportunities for deep learning surface in the course of the volunteers' actual work with youth. There is also a risk that interactions that could be harmful to youth might arise. For these reasons, it is important in the design of a volunteer value-add program to encourage and scaffold opportunities to interact with paid staff and in community with other volunteers. These structured interactions allow for course corrections at the individual and programmatic levels. When handled well, they also afford professional development for volunteers, which is not only beneficial to the program but also valued by volunteers, thus deepening their commitment to volunteering and to the organization.

READ718 recognizes that volunteers learn most when they get substantive support in real time when engaging with a specific student on a specific issue. Consequently, every session for each tutor and youth is specifically structured by staff. When the tutor arrives at the storefront for their session, they are provided material that builds on the last session and the tutor's own 


\section{All Hands on Deck}

notes, and they discuss the session plan with staff. Tutors regularly mention that this level of organization-the professional support they can easily access, combined with the direct incorporation of their input-provides a satisfying experience. When they arrive at the storefront, the time they spend is productive; they are both seen and heard.

To further enhance the experience for tutors, READ718 hosts appreciation hangouts so tutors can get to know one another and build a sense of shared purpose and community. Also, at a tutor's suggestion, interested tutors and staff meet once or twice a cycle to discuss readings related to issues of social justice, race, class and privilege.

\section{Assessing Impact}

Assessment is a necessary component of any well-designed program. The primary value to an organization is the data that allows for tweaks and adjustments that improve the quality of the work over time. In a volunteer value-add program the overriding questions are: How well is the work serving the youth and how might it be done better? Staff will have valuable perspectives, as will volunteers. It is useful at the strategic planning stage to think about what to track and how to reasonably gather qualitative and quantitative data, and to bring this into the program design. As important as it is to gather input and data for supervisors, it is valuable to share it and use it, as appropriate, in a community of both staff and volunteers to improve the program.

For many reasons, not least because of the investment that READ718 makes in recruiting, screening, training, and supporting each tutor, it is beneficial for tutors to return for multiple cycles. Roughly $50 \%$ of tutors in one 10-week cycle return for the next one (READ718 does not have data on tutors who take a hiatus and return). The main draw for tutors is documented to be the well-defined role, the intimate engagement with youth, the time-limited commitment requirement and the quality of the support and professional development they receive.

In terms of the impact of the volunteers on youth literacy, READ718 tracks student progress (reading and comprehension in relation to grade level) and uses this as one input in guiding tutors and customizing work with individual youth. In the spring 2019 cycle, for example, 89\% of youth advanced at least one Fountas and Pinell reading level. As a relatively young program, READ718 is only now accumulating sufficient data to evaluate its overall impact; they do not yet know, for example, whether their tutors are as effective as paid professional staff in advancing youth literacy. Nor do they yet know whether their work results in lasting improvement. 


\section{All Hands on Deck}

READ718 also specifically solicits volunteer feedback, through a survey after each 10-week cycle. Tutors are asked, "What makes this a positive and/or negative experience for you?" Tutor input is thoroughly reviewed and used to improve the program experience for youth and volunteers alike. What is distinctive about READ718 is the transparency with which information is shared with volunteers. Just as individual student progress is shared and discussed, so is the impact of the overall program. The result is that volunteers are vested in helping staff shape the program for improved outcomes for youth.

Soliciting feedback from volunteers regarding their own participation and the strengths and weaknesses of the program is a critical way to engage volunteers and demonstrate how much the organization values their perspective. As important as soliciting feedback, is its actual integration into program design. This is a valuable element of program sustainability underweighted in other models of volunteer program administration (Boyce, 1971; Lawson \& Lawson, 1987; Culp et al., 1998).

\section{Conclusion}

A volunteer value-add program is not for the faint of heart. Whereas the volunteer-dependent organization is, by definition, devoted to supporting its volunteers in their interactions with youth, the value-add organization has a paid staff that is committed to serving youth, and is also likely stretched in their work responsibilities. In a constrained resource environment, it is logical to seek ways to extend service economically. Volunteers are a compelling potential supply of brains and brawn and the benefit of their engagement can accrue not only to an organization, its staff, and the youth it serves, but also to the volunteers themselves. However, there are undeniable risks to an ill-conceived program. One significant risk is that the volunteers cause some kind of harm to youth as a result of a lack of cultural competence or intentional empathy. There is also secondary risk to the organization's reputation when volunteers are underprepared, ill-supported, isolated, and otherwise frustrated. An age-old marketing truism holds that an unhappy experience gets related about seven times; this negative word-of-mouth diminishes the reputation of an organization and negatively impacts fundraising.

For all of these reasons we reiterate that the critical precursor to launching a volunteer valueadd program is a fulsome discussion by leadership, board, and staff of the goal of the program and its connection to the mission. Leadership and board must realistically assess the resource implications of a program and allocate the necessary funds, just as a volunteer-dependent 
organization would do. The program may not require a new full-time management position, but it cannot be an added responsibility for an already fully employed staff member. There must be both bandwidth and priority accorded to the position. Advance planning for all aspects of a program-outreach, screening, preparation (including cultural competence development), assessment and improvement, combined with attentive implementation-is the most assured way to have a strong initiative. We stress in particular the value of affording ongoing support and development to volunteers, together with the sincere and responsive use of volunteer feedback. Substantive and consistent scaffolding of volunteer work safeguards youth and gives volunteers confidence. The incorporation of valuable ideas provided by volunteers reinforces a sense of commitment between the organization and the volunteers. Together these actions contribute to positive experiences for youth and positive reputational advantage for the organization.

\section{References}

Boyce, M. V. (1971). A systematic approach to leadership development. USDA, Extension Service. (ERIC Document Reproduction Service No. ED 065763).

Culp, K., III, Deppe, C. A., Castillo, J. X., \& Wells, B. J. (1998). The GEMS Model of volunteer administration. The Journal of Volunteer Administration 16(4), 36-41.

DiAngelo, R. (2018). White fragility: Why it's so hard for White people to talk about racism. Beacon Press. Dubose, D., (2014, December). The nonprofit sector has a Ferguson Problem. Nonprofit Quarterly. Eisner, D., Grimm, R., Jr., Maynard, S., \& Washburn, S. (2009). The new volunteer workforce. Stanford Social Innovation Review (7)1, 32-37. https://ssir.org/articles/entry/the new volunteer workforce

Galindo-Kuhn, R., \& Guzley, R. (2002). The volunteer satisfaction index: Construct definition, measurement, development, and validation. Journal of Social Service Research 28(1), 45-68. https://doi.org/10.1300/J079v28n01 03

Lawson, A., \& Lawson, S. (1987). Congregational workshop: Volunteerism in the church. Journal of Volunteer Administration 5(3), 35-40.

Lindwall, J. (2002). Will I be able to understand my mentee? Examining the potential risk of the dominant culture mentoring marginalized youth. Journal of Youth Development 12(1), 72-91.

\section{https://doi.org/10.5195/jyd.2017.485}

Nelson, H., Netting, E., Borders, K., \& Huber, R. (2007). Volunteer attrition: Lessons from Oregon's volunteer long term care ombudsman program. The International Journal of Volunteer Administration 24(5), 65-72. 
Journal of Youth Development | http://jyd.pitt.edu/ | Vol. 15 Issue 4 DOI 10.5195/jyd.2020.877 All Hands on Deck

Netting, F., Nelson, H., Borders, K. \& Huber, R. (2004). Volunteer and paid staff relationships: Implications for social work administration. Administration in Social Work 28(3-4), 69-89. https://doi.org/10.1300/J147v28n03 04

Rogelberg, S., Allen, J., Carney, J., Goh, A., Currie L., \& McFarland, B. (2010). Employee experiences with volunteers: Assessments, description, antecedents \& outcomes. Nonprofit Management and Leadership 20(4): 423-444.

Smith, R. (2013). Mission vs. money: Surveying the landscape of museum ethics. New England Museum Association News, 371), 8-13, 22.

https://nemanet.org/files/3013/8602/0752/Mission vs Money.pdf 